\title{
ANALYSIS OF THE ICONS USED IN GRAPHICAL INTERFACE OF MOBILE APPLICATIONS
}

\author{
DOI: 10.17261/Pressacademia.2020.1194 \\ JMML- V.7-ISS.1-2020(2)-p.18-27
}

\section{Leyla Artuk}

Dicle University, Department of Computer Technology, Computer Programming, Diyarbakir, Turkey. artuk@dicle.edu.tr, ORCID: 0000-0001-8160-4161

Date Received: December 22, 2019

Date Accepted: March 25, 2020

To cite this document

Artuk, L., (2020). Analysis of the icons used in graphical interface of mobile applications. Journal of Management, Marketing and Logistics (JMML), V.7(1), p.18-27.

Permemant link to this document:http://doi.org/10.17261/Pressacademia.2020.1194

Copyright: Published by PressAcademia and limited licenced re-use rights only.

\begin{abstract}
Purpose- The purpose of this research is analyzing the effects of the icons that are used in the interfaces of mobile applications on the usage of these applications.

Methodology- The icons are analyzed according to their abstraction, color usage, resolution and their adaptation with each other and checked if they're affecting the understandability, readability, and globality of interface.

Findings- Icons used in applications, which are distributed within application markets such as Google Play Store, IOS App Store and Windows Phone Store, were examined.

Conclusion- It has been determined that the importance of using icons in mobile application interfaces design should be announced more clearly. It is considered that instructing students who study graphic design at universities away from the use of ready-made icons and towards icon design may contribute to efforts in this direction.
\end{abstract}

Keywords: Icon, mobile interface, mobile application, graphic design.

JEL Codes: L80, L86

\section{INTRODUCTION}

Development of mobile communication infrastructure, price reduction in mobile devices, expanding of the mobile applications and depending all of these factors usage of the design techniques that are being used for a long time in desktop computers in mobile devices in a same or transformed forms have made graphic design to gain a prevalent place in mobile world. Since mobile devices have fewer hardware qualifications than desktop computers, small screens due to their portability, inputs as touchpad keyboard instead of classical keyboards and outputs sharing an important portion of the screen, the graphic design process differs in mobile applications. The difference requires graphic designers, who have a crucial role in designing the interface of mobile applications, to use a different language along with different procedures and tools.

Mobile interfaces need usage of a global language due to the fast-worldwide expansion potential of mobile applications, along with its qualifications that are mentioned in the previous paragraph. This language makes the application can be understood by different people from different nations. Icons are one of the crucial components of this language. Icons that are formed through the procurement of the symbolization of instances like a command, message, routing, and warning, make the applications userfriendly, accessible, understandable and global.

The purpose of this research is the analysis of the effects of icons that are used in the interfaces of mobile applications on the usage of these applications. 
Even though, the software developing manufacturers seem like they have enormous staffing and financial power, developing new mobile applications became considerably easy and fast. In many instances, these applications have proven themselves for bringing profits proportional to their success. Nowadays, interfaces are being designed for almost every device that has electronic control growingly. Spreading usage of mobile applications increases the number of rivals for designers and requires them to bring a more professional perspective to their works.

The most important factor that influences the success of mobile applications can be accepted as being independent of the language that makes them useful all over the world. Furthermore, in order the application to be used easily all over the world, icons can be seen as the biggest helper of the designers.

Previously used in the web design, also in mobile design for a long-time not so user-friendly designs were used. However, with the development of web technologies and web design, improvements like the quick start of websites with rich graphic content, design of the more understandable and readable graphic design with more talented and accessible tools have started to be seen on mobile design, too. With the improvement of mobile communication technologies mobile application development platforms have spread out and diversified and its supporting design tools have also become more talented. Along with these, the unfair rivalry due to design tools in mobile applications has disappeared and the talents of the designers became the only superiority criteria in the competition of mobile applications.

The designs of icons provide the universalization which are the most important criteria of the success of mobile applications, indirectly affects the application's success. This research can be considered as a directive work since it is one of the limited works that analyzes the effects of icons to the success of applications.

A mobile which means portable expresses that mobile devices are also small and portable. These devices are stated as touchoperated, have a small keyboard and provide the users the ability to carry the device wherever they go. Even though various mobile devices have similar qualities, there are differences between every device due to their operating systems (Bilgili, 2014: 7). Communication is formed through technologies that are used in mobile devices like Wi-Fi, Bluetooth, and GPS. Hardware like cameras, microphone and sensors are used to get in touch with the external world and power supply is usually provided through lithium batteries (Bilgili, 2014: 7). The portable devices that are suitable for personal use, provide technologies that facilitate communications like GSM, GPRS, Wi-Fi, and 3G, has small device size, battery size and battery capacity are named as a mobile device (Mıhcl, 2014: 12). Mobile devices gather features like audio recording, web browsing, photography, music, video, and messages in a pocket or portable devices, compared to the computers. Even though these devices provide these features that computers have, with small hardware it is not expected from them to carry out these actions as fast and clear as personal computers. (Namlı, 2010: 6).

The field of human-computer interaction has an interdisciplinary structure. Computer science, psychology and cognitive science form the foundation of this field (Dix, Finlay, Abowd and Beale, 2004). When IBE was a sub-branch of cognitive science in the 1970s, its purpose was to exercise cognitive science methods in software development (Caroll, 2003). It was assumed that general perception, motor skills, problem-solving, language and communication rules can conduct the design of technology products. Cognitive psychology themes such as human perception, information processing, memory as well as people's abilities and boundaries are very important subjects for designers working in the field of IBE.

Users utilise new generation mobile communication devices (smartphone-tablet) by tapping on their heat-dependent touchscreens. This requires the user to give direct commands to the interface and interact with it. In addition, major questions emerge concerning how the interface designs of these devices affect the performance and to what extent they facilitate visual communication.For these reasons, it is intended to examine the interface designs in terms of basic graphic design principles (balance, proportion, verbal-visual hierarchy, visual continuity, integrity and emphasis) and provide a comprehensive analysis of interfaces' impacts on usability by making use of the inquiry-based methods in evaluating usability. Designing the interface by following basic graphic design principles ensures the success and usability of the developed design. Since the user is in direct contact and interaction with the interface, it can be stated that the interface design directly influences the usability of the mobile operating system. For this reason, our study was evaluated by examining the icons within the graphic interfaces of mobile applications. 


\section{LITERATURE REVIEW}

The mobile applications generally used in tablet computers and smartphones, answers many needs of daily life. The development of mobile applications that has a big importance for saving time in the developing and unlimited world of the Internet, has accelerated along with the development of tablet computer and smartphones. Usually used in communication, banking, media, and entertainment, these mobile applications provide people to deal with their transactions in these areas independent from their computers. (Beyaznar, 2014: 33). Due to the easily reached nature of the Internet and the development of Internet-based technologies, almost all services are easy to reach. With the spread of mobile applications, the internet, which provides services like shopping, entertainment, and education, became even more useful. Mobile applications that provide fast and easy usage of Internet services, can be used in different devices according to its operating system. Widely spread IOS id used in Apple devices, Microsoft Phone (Mobile) is used in some models of Nokia, Android is used in the for most of the mobile devices that are left outside of these (Bilgili, 2014: 10). The applications that are designed for mobile devices are called mobile applications. These types of applications are software, and even though their development process and design structure are similar to computer software, they differ from them because of their development place and usage of hardware and (Namlı, 2010: 3). In the present day, along with the expansion of the smartphone and tablet market, the number of mobile applications has become 1,2 billion. According to $\mathrm{ABI}$ research reports, 56 billion applications for smartphones and 15 billion applications for tablets are uploaded to the internet in 2013. \%58 of smartphone applications are using Android, \%33 of them are using IOS and \%4 of them are using Windows. In tablets, \%75 of the applications are using IOS and \%21 of them are using Android. Before 2017, the expected number of mobile applications will become more than 200 billion (Aslan veYavuzer Aslan, 2013: 83).

Before then, there were regular phones used for only making calls however nowadays they left their place to the smartphones that have improved operating systems and applications. Smartphones are the devices that use cellular communications for connecting to the internet besides Wi-Fi (Bilgili, 2014: 7-8).

Tablets are designed for application usage instead of communication in terms of functionality. Even though there are some models lets telephone calls, they are not usually preferred for this type of communication due to its weight and other qualifications that are not ergonomic. Usually, it is preferred since it provides a widescreen and more comfortable keyboard usage for applications that are hard to use on a telephone screen.

Products like smartwatches, fitness bands and Google Glass are the milestones of wearable technology. The most used voice command system in wearable technologic devices is the artificial intelligence assistants named Siri and Google Now. The device that is shaped as Bluetooth earphones and communicates through Google Glass and Apple iWatch undertakes the assistant role, answers the commands and informs people about timely information. These kinds of devices also can answer all the questions that are asked such as the birthdays or addresses of people's friends. These lightweight and small wearable devices can be used in anywhere easily $(\mathrm{CIO}, 2015)$.

The mobile interface is the text and graphical elements and their design that provides users to control the opportunities of the application. These interfaces that detect user-friendliness also indirectly affect the commercial success of the devices where they are used in. User-friendliness one of the criteria that determines the buying preferences of the customers and it is one of the implications of this situation.

Interfaces are the designs that provide communication between user and software or application. They are designed as text commands during the times when graphic screens are not fast and powerful enough. With the improvement of graphic technologies, interfaces are started to be equipped with graphic elements and became easy to use. The interfaces that are equipped with graphic elements are named as "graphical interface" or "graphical user interface".

Graphical interfaces are the interfaces that are designed by using texts along with visuals and pictograms for users to use devices like computers, mobile devices, ATMs, photograph machines, media players, satellite television systems more easily. These interfaces direct the experience of the users and make them focus on the targeted point. Messages, warnings, redirections, and statements are reached to customers according to the purpose of used design. Users need a graphical interface to see the resources provided by the device regularly.

Graphic design has three main tasks: informing, persuading and giving identity (Düz, 2001: 1). In the design of the mobile interface, these are determinants for main subjects that designers should consider. The criteria for successful graphical interface design are directly related to the success in performing these three tasks and this should be taken as the main goal in interface design where 
interface functions are carried out properly. The studies in interface designs imply that in order these functions to be performed, the simplicity of the design, usability, understandability, and accessibility should be taken seriously.

The development of graphic design causes various researches about user experiences. Since interfaces that are users directly interact with, were started being developed with processes where users were involved, "user-centered design" policy was born, and usability of interfaces was emphasized more and more eventually. To understand usability, an inspection of the principles of user-centered design would be useful. According to the accepted description, a user-centered design process means that the design practices conducted in light of the information taken from user experiences (Gürses, 2006: 12-13).

The distinguishing feature of the main interface parts is that being directly the elements of interface monitor. The interfaces that are used in mobile devices are usually text fields, buttons, and menus. Almost in every graphical interface, the main mission facilitates to reach documents and programs through icons. In these types of operations, even though the frequency of use of icons is high, the low number of scientific researches is surprising (Bryne, 1993: 446).

Icons which are important tools in graphic design are used in different instances other than electronic settings. They are widely used in various places such as traffic signs, guidance signs, product labels. Since they are designed as recognizable by anyone easily, it can be easily understood that language barriers are removed and with that icons became a universal language (McDougall \&Reppa, 2008: 1257).

Signs are grouped into three groups as icons, indexes, and symbols. Icons have the simplest and most basic outlook compared to the other two. An icon carries the form of the represented object; thus it resembles this object stylistically. While the abstract of the indexes and symbols are developed with an interpretive approach according to the meaning of the represented object, abstract of icons happens stylistically. An object is still recognizable in terms of figure, even it is abstracted as an icon (Buchler, 1991: 102).

In electronic settings, icons have gained a different dimension and their spread has accelerated with the usage of graphic design. It is not wrong to say that usage of icons, which are one of the crucial parts of mobile applications, in electronic settings has started with the Internet.

Due to their important functions like instruction, information, and warning, icons are placed in the communication channel conducted with eyesight. Because of this feature, icons are used instead of texts where efficient communication is needed with users and help to save communication time (InançUyan, 2009: 195).

Icons, which consist of a crucial feature of the graphic design, should have some qualifications in order design to reach its goals. Foremost among these, the requirement of compatibility between the visual features of icons with their functions (Inanç Uyar, 2009: 195). Along with these, icons must have three main qualities which are generality, abstractness, and style. Pictograms and symbols also must have these three qualities. (Fonseca, 2001: 76-87).

User interfaces play a crucial role in human-computer interaction. The user interface design of a system or program is vital to the flow and usability of the system. Mobile devices and technologies are one of the most substantial examples of human-computer interaction. Mobile applications are programs with user interfaces built within the structure of certain criteria. The aim of the study is to test two different mobile applications with the same procedures by users in line with defined principles and provide the opportunity to access the correct information about the two application's user interfaces (Akyol, 2014).

Although mobile devices have become an essential part of daily life, standards for mobile user interface (UI) design models have not yet been fully ascertained. Most of the mobile website interface designs are based on the website models developed for the desktop. However, these interfaces are not fully compatible with mobile screens and prompt some difficulties for users. By providing an overview of current studies on mobile website design patterns, solutions for the most popular design and usability problems on mobile compatible websites have been investigated in thıs study (Dinç, 2018). 


\section{APPLICATIONS}

Icons of the applications that are distributed in Google Play Store, IOS App Store and Windows Phone Store will be analyzed. In order to analyze these icons, the applications are first downloaded then the features on these applications have been reviewed and interpreted. Below, Facebook, Alim Advanced Accounted System, IBB Cep Traffic among these applications are examined with visuals along with databases and comparisons are made. The good and bad features of these applications have been shown.

\subsection{Facebook}

The mobile application of Facebook, the most widespread application of the world, is one of the heaviest and most active users of the icons. The main screen Facebook's mobile application is formed of 4 parts. First of them is the banner bar that has a username, second is notification bar, third is the timeline and fourth is sharing bar.

Figure1:Sample of Facebook Interface

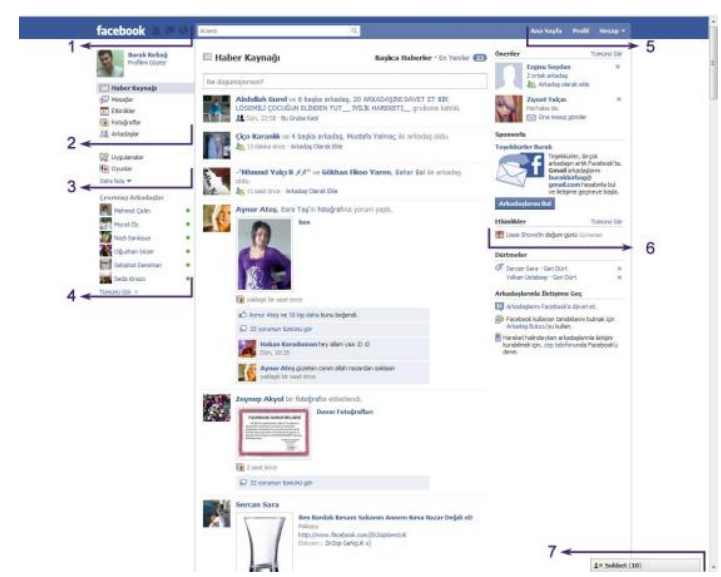

There are two icons in the banner bar, the first of them operates the search process which is heavily used on Facebook. The search icon is shown as a magnifying glass that is identified with search operation and also used by Microsoft's Windows and Apple's MacOS for many years. Facebook has four main search operation which is for people, pages, groups, and events. The simplicity of the magnifying glass symbol in the search icon is caused by being able to do all of the search operations when clicked the icon. When inspected according to the functions of graphical icons; the search icon can be considered universal since it has light colors in the dark base. The second icon on the banner bar opens the messaging menu, one of Facebook's most used functions. The symbol is formed from lines body and head symbol and lines that resemble menu rows. Messaging menu icon is designed with the same colors as the others which makes them be in unity with the other elements of the banner bar. The icon that has the function of choosing the person to message before reaching the messaging screen, expressed from a human symbol and successive lines listed horizontally. Even though the simplicity of the sign and color-based relation strengthen the readability, the horizontal lines can be confused with drop-down menus. However, for the users of Facebook, this confusion is not at a disturbing level since the usage of messaging applications is high. There are 5 icons on the notification bar of the interface which are Timeline, friend requests, inbox, notifications and profile page, respectively. The icons besides profile page numbers that represent notification counts can be seen. When there is no notification, these numbers are not visible. Users can check the details of the notification by clicking the icon when there is a number. Icons are designed with a light color on a light base; however, this is not a problem since it should be clicked when there is a notification. When icons are chosen its color darkens, so users can understand which page they are currently on. Timeline is the screen where contents that are followed by users are shown. The content on this screen is shown in a window where the profile picture and name of the sharing person are placed in the upper left side. Timeline icon on notification bar is formed as a box similar to the window it was published that has a frame on the upper-left side and lines next to this frame. Considering the small screens of mobile devices, this icon is insufficient in a symbolic sense. It may be remembered easily because of the usage habits of the Facebook users. However, this situation does not eliminate the need for better icons representing the timeline. Friend requests icon is formed by putting a two-person symbol next to each other. If it is looked out closely, it is easily noticeable that one of them is male and the other is female. With its symbol, the icon emphasizes 
the universality more clearly and at the same time associates the friendship concept in a strong way. It is also sufficient in terms of readability and understandability. The inbox icon is designed as a speech bubble in a simple way. The usage of a speech bubble in other desktop applications as a messaging symbol increases the understandability of the icon.

The notification icon is designed as a world symbol. This symbol is considered as meaningful when it is thought that it symbolizes the page where all of the notifications from friends all over the world listed in. However, since the notifications belong to the text, image and video content, there is a need for a more understandable symbol semantically. The profile icon is formed from three lines one under the other and it resembles a menu. The icon that opens the page where frequently used operations, pages that are operated by users and applications listed, is not related to the content in terms of meaning however it reflects the list form of the page. Even though the symbols in the notification bar does not have successful designs since Facebook has an enormous user database all over the world the icons, they designed are quickly become relevant among users and even serve as a model for the other applications. There is an icon on the upper right side of the Timeline that resembles " $v$ " or point of an arrow. This icon opens a menu that lists some functions like hiding the post, unfollow the sharing user about the post in the window. The simplicity and understandability of this icon are up to the user experience. On the bottom of the window, there are like, comment and share buttons. The icon on the like button is designed with a hand where the thumb is on air that means acceptance. This symbol, which is identified with Facebook in many places, is used for liking the post and informing the other users about it. There is a speech bubble on the comment button and an arrow that is turning right on the share button. Since the speech bubble is supported by text, there is a low possibility that confusing this icon with the messaging icon. The arrow symbol on the share button is previously used to symbolize the forward command in many e-mail services, which is considered as a suitable choice for understandability in a button that forwards other Facebook users. The sharing bar has three buttons that have icons supported by big texts. First of them is the share button that has an icon designed as a pencil symbol. The icon opens a box where users can share text, image or video about any topic. Since pencil symbol is used in many applications to open a blank page or edit the existing content, the understandability of the icon is high for the users. The second button in the sharing bar is an image sharing button that has an icon shaped like a photography machine. It quickly opens a window where users can easily share the images. The universally known photography machine shaped icon is also supported with text. The third button in the bar is the location button where users share their location. There is an icon in this button which is known by navigation devices and it is supported with text.

The common characteristics of icons that are inspected can be summed up like this. Simplicity: There are very few illustration elements in the design of the icons. Readability: All icons are universally known symbols. Understandability: Even though some symbols may be confused with others used in some icons, these icons are considered exceptions and recognizable due to Facebook's worldwide popularity. Consistency: All of the icons are designed in the tones of blue which is the color of Facebook's theme so there is a color uniformity among them. Even though there are different design templates used in selection groups like the status bar or title bar, in terms of abstraction level and color all of the icons seem compatible with each other. The same icons are used in different versions of Facebook in different operating systems. According to the screen size or choice of the user the number of the icons in the toolbar changes. Along with that notification bar in IOS positioned on the bottom and in Android and Windows Phone on the top. These are some of the few differences between the appearance of the application in different operating systems. Besides these, according to the user choice, the icon of the chat module Messenger can replace the notification icon of the messaging.

\section{2. Âlim Advanced Accounting System}

Âlim Advanced Accounting System is a free application which is an example of the mobile version of pre-accountancy software. It can perform pre-accountancy functions and debit/credit tracking while aiming for competitive advantage with its information security function. Application interface welcomes the users with a menu with 9 choice options with icons. One of these icons is the excavation work symbol that means "under construction". This symbol shows that the related menu option is still being prepared. The other icons are about the functions of the application. The icon is formed with three different person symbols that have different colors. The fact that the faces in the icon do not have organs like ear, nose, and eye strengthens the abstraction and as a different fact, there is more than one person on the icon which emphasizes the implication of the listing function more. The colors that are used in the icon are far away from assuring the users which are expected from these types of accountancy applications. Along with that, usage of three different colors reminds the function of the icon which shows different types of checking account together. Icon is designed as electric plug. In the icon's design which based on the blue color grey and yellow was also used. The simplicity isn't lost even though the shadowing technique is used in the design. Symbolization of electric plug seems enough in terms of understandability due to its easily recognizable shape, however, irrelevance between the icon and its 
function reduces this understandability. The icon has the function of connecting and interacting with the mobile device and computer that the application is on. Usually symbolized radio waves are used in the icons that have this type of function and when the fact that the mobile devices are wireless is considered, choosing the icon as an electric plug that has a wire seems like an erroneous decision. Coin symbols and VISA and MASTERCARD logos were used in the "Cash/Credit Card" button that lists the user's credit card and cash assets. The icon design is consistent with the function of the button however in terms of abstraction it is not sufficient. Usage of green, blue, yellow, red and grey colors in the same percentage in the design and existence of many symbols reduces the understandability of the icon. "Bank Accounts" button that lists the bank accounts of the user registered in the app has a symbol of the business center. The way that symbol is designed with a grey color which evokes seriousness, formality, and diplomacy, makes people think that icon is about the official and legal processes about banks. However, considering the colors of other symbols in the interface and their functions, using more abstract symbols for listing the bank accounts would be more suitable. An icon designed with a dollar sign and a car that has vivid colors is used in the "Assets" button that lists the user's vehicles, immovables, and bonds. The way that the car symbol has shadow and reflection details makes the icon insufficient in terms of abstraction. Furthermore, the color transition between green and white in the dollar sign reduces abstraction. "Reports" button that shows the situation of the assets, accounts, general debits/credits, and vaults as a text has an icon of a white paper symbol with lines. Since the icon has the functions of reporting and e-mailing the text-only report, it is not sufficient in terms of understandability. Compared to the other icons, the resolution of the icon in the "Reports" button is low which creates a mismatch between the icons. "Tools" button that opens the menu where users can update the forex rates and make a report about the system info of the mobile device has an icon consisted of a screwdriver and key symbols that are frequently used in buttons that have these type of functions and has an optimal understandability level. However, the way that the button named "Tools" is inconsistent with its functions. Despite this situation, the icon is successful in terms of abstraction because it has been designed with the symbols that are known universally and without redundant details. "Settings" button that opens the menu which has functions like user definition, backup, defining of the currency used, initialization of the data has an icon consisted of three raddled gearwheels. The understandability of the icon is high due to the simple design of the gearwheels. Since the symbols have grey tones and consistent with the function of the icon the readability is also high. When the icons used in the interface of Âlim Advanced Accounting System are analyzed, the following issues have arisen. The resolution of the Reports button is lower than the others. There is no consistency in the usage of colors, vivid colors are used in only some icons. Even though icons have the same sizes, the sizes of their buttons are different. When the understandability of icons is evaluated, it can be seen that the tags on the button have supported understandability significantly and without them, it is hard to understand the functions of most of the icons.

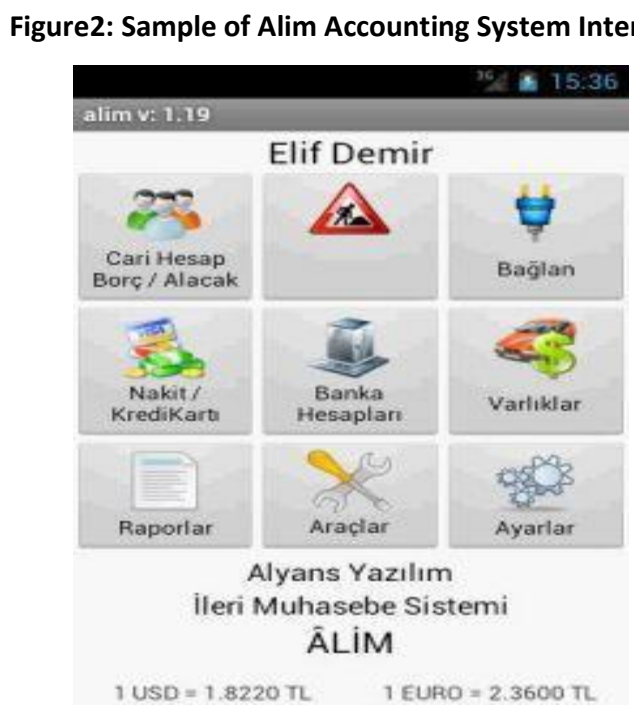

When the icons of the app are evaluated these facts would show up: Simplicity: It can be seen that there is no emphasis on the simplicity and abstraction of the icons. Since various colors and symbols are used, they give a complicated image. Readability: Generally, icons are at a sufficient level in terms of readability due to their resolutions and sizes. Understandability: The icons 
were designed with symbols that fit their functions; therefore, understandability is sufficient. However, some misleading symbols have also been used. Consistency: In terms of resolution, color usage, abstraction level and variability of symbols, there is no consistency in interface icons. However, the sizing of the symbols is one of the rare elements that are consistent. Since there is no version of the app in different operating systems than the Android version, the comparison between different versions wasn't conducted.

\subsection{IBB Cep Trafik}

IBB Cep Trafik which is provided by Istanbul Metropolitan Municipality aims to give instant citywide traffic information. It also provides up-to-date traffic camera recordings, locations of the parking lots, the journey time between different locations. The interface screen of the IBB Cep Trafik welcomes users with a map showing the current traffic conditions. The interface screen consists of the title bar on the top, map on the middle and status bar on the bottom. Status bar and title bar can be hidden if wanted, so there would be more space for the map. Logo of the Istanbul Metropolitan Municipality and name of the application are located left of the title bar, while the menu and announcements are on the right. The announcements button has an icon designed as a megaphone. This icon seems suitable since it opens the announcements, however because of the chronical traffic problem of Istanbul makes announcements and due to that the red area on the megaphone permanent and requires the usage of another suitable icon in terms of understandability. The menu button on the title page has an icon consisted of three horizontal lines. It opens the menu where functions like notifications, weather forecasts, and video call for the people with impaired hearing listed, and due to this characteristic of the button, the abstraction can be considered successful. Menu icon and all elements of the title bar is designed with light colors on the dark base which keeps the readability at a high level. On the map area of the IBB Cep Trafik, there are 6 icons in a floating position. One of them is for information purposes while others are functional. Traffic Intensity icon gives the traffic flow situation in terms of percentage. This icon indicates the traffic density with text which is supported with a doughnut chart at the same time. The icon is placed on a base with a blue color which is frequently used in the design projects of the Istanbul Metropolitan Municipality. Since the numbers that indicate the traffic density is written with a font that has high readability with enough size, the readability of the icon seems sufficient. The gradient effect from green to red based on the density level is used on the doughnut chart. The way that green, which is the color of trust, is used when traffic density is low and red, which is the color of excitement, is used when the traffic density is high, increases the understandability of the icon. Zooming icons placed in the middle of the application interface is designed as semitransparent buttons that has plus and minus signs. Both icons are designed with a simple blue color on a white base and they have the same size, transparency, allocation and color values. Since most of the navigation and map applications have the same signs, the readability of these icons is strong. The share button of the application has an icon that has been used in other applications as a sharing button for a long time. This icon has been designed similar to the other buttons on the map as blue color in the semitransparent base. Since the size, color and allocation of the icon are the same as the other icons, there is harmony between the icons among the map. The location icon is similar to the other icons that are used in the other map applications with a function of locating the mobile device with the help of GPS and focusing the map to this location. Since these similarities ease the readability for the users, the location icon of the IBB Cep Trafik can be also considered as readable. Satellite/Map Appearance icon has the function of changing the appearance of the map Due to the detailed drawing, understandability has been reduced in this icon. The icon has the abstraction of a half-opened folded map, due to the thickness of lines it is weak in terms of readability. There are four buttons on the status bar of IBB Cep Trafik. First of them opens the window that shows information about the intensity of bridge traffic which is one of the most intensive points in Istanbul. The icon has been designed as a draw bridge that resembles Boğaziçi Bridge in black color and has a high understandability. The second button of the status bar, "Cameras" enables switching to the page that shows images from traffic cameras placed in Istanbul. Icon of this button is a camera symbol that is abstracted and easily understandable. The third button "Carparks" shows the symbols that represent carparks all over the map. The icon on this button is symbolized with a universal parking symbol, the letter "P". The fourth button of the status bar "Journey Time", makes pre-located symbols visible and gives the estimated current journey time between two of them selected according to the traffic intensity. The icon that is designed according to its function, with the usage of car and clock symbols together. Since the car does not have any details besides its wheels and the clock is big enough to fill the icon area, the readability of the icon is strong. Bridges and journey time buttons on the status bar are not sufficient in terms of abstraction. Compared to the others, cameras and carparks icons have the most frequently used symbols so their abstractness is far from creativity but can be considered successful. When evaluated, the icons in IBB Cep Trafik are separated into three regions and in each region, icons are consistent with each other. The icons on the map are translucent to keep the visibility of the map, however, this situation does not have any negative effect on the readability of the buttons. The resolution of the buttons is high, and their color is blue which is frequently used in the designs of governmental 
agencies. When the icons of the app are evaluated these facts would show up: Simplicity: The simplicity is generally sufficient due to the level of the abstraction, however in some icons, complicated symbols are used as a contradiction. Readability: Icons have sufficient readability levels since icons are widely known and their resolution levels are high enough. Understandability: Despite the fact that the icons were understandable parallel to their readability, understandability is weak in some icons which do not have unknown symbols. Consistency: When the interface is inspected as segmented, in each segment icons are compatible with each other according to especially their colors, abstraction levels, and sizes. However, considering the interface as a whole, there is an evident inconsistency between the icons. The way the icons in the map area are designed differently than the icons in the status bar can be considered as an example of the source of this inconsistency. When different versions of IBB Cep Trafik in different operating systems, IOS and Android apps resemble each other significantly. In these two operating systems, the same icons were used, and they are the same in terms of position, size, resolution, color, sorting, and functions. In contrast to that, there are big differences in the icons of the Windows Phone app. Even though, associations of icons are similar they are completely different in terms of graphic elements such as color, size, framing, and transparency. The difference in the Windows Phone app can be attached to the fact that its late release. The fact that application development environments for IOS and Android take time for supporting Windows Phone, makes Windows Phone app different than the others.

Figure 3: Sample of IBB Mobile Phone Traffic Interface

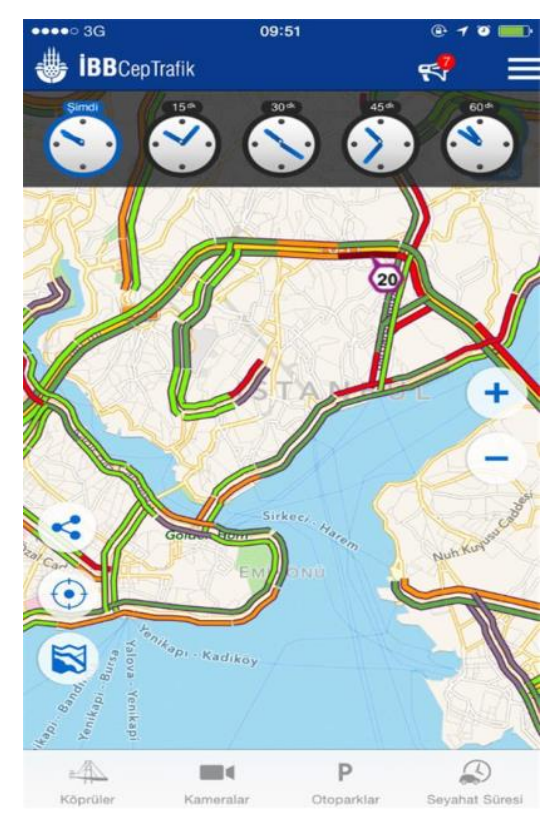

\section{CONCLUSION}

In this research, the icons that are in the graphical interface of the currently used and randomly selected mobile applications are inspected. The results of this inspection can be listed as below:

The qualifications of the icons used in the graphical interface of mobile applications indirectly affect the success of the application.

In the applications that are inspected including widely popular ones worldwide, the icons that are weak in terms of understandability are used. In widely popular applications these kinds of icons are started being no longer a major problem, furthermore, they are being recognized with their function in these applications.

In the applications that are not mainstream, new design attempts haven't been observed and the icons that are known with their functions and used previously in other apps unimaginatively, so they have reduced the risk of eliminating the readability and 
understandability of the application. In most of the applications, icons like the menu, calling, people list, and settings are the same as each other, so these icons became universal.

Due to the development level of hardware in mobile devices, there were not any resolution problems in icons, only a few were observed as in the form of design faults.

In the applications designed by professional companies, the color usage was taken place according to the corporate identity design rules where in the other applications the icons that have colors dissonant with the functions of the apps were designed. As a result of the research, icons used in today's mobile applications affect readability, understandability and as a result of the universality of the applications. Abstraction, color usage and compatibility with each other of the icons used in the interfaces of the mobile applications affect the understandability, readability, and universality of the app positively.

Considering the results, the need for announcing the importance of icon usage in the design of mobile application interfaces has emerged. Directing the graphic design students to design new icons from using icons on hand, may contribute to the efforts in this case.

\section{REFERENCES}

Akyol, G. (2014). Mobil Uygulama ArayüzlerininincelenmesiÜzerineBirÇalışma, ISITES 2014.

Aslan, B. veYavuzer Aslan, F. (2013). Mobil ProgramlamanınÖnemiveBirMüfredatÖnerisi, 3.Uluslararası MeslekYüksek Okulları Sempozyumu, (2-4 Ekim 2013).

Beynazar, B. (2014). Mobil Uygulamlarda İnsan Kaynakları MetrikleriTasarımı, YüksekLisansTezi, Bahçeşehir Üniversitesi SosyalBilimlerEnstitüsü, İstanbul.

Bilgili, M.ì. (2014). AdaptifBağlamBilinçli Mobil Uygulama Geliştirme, YüksekLisansTezi, Gazi Üniversitesi BilişimEnstitütü, Ankara.

Buchler, J. (b.t.). Philosophical Writings of Pierce, New York: Dover Publications

Byrne, M. (1993).Using Icons to Find Documents: Simplicity Is Critical, School of Psychology and Graphics, Visualization, and Usability Center, Atlanta.

Caroll, J. (2003). HCI Models, Theories, and Frameworks. San Francisco: Morgan Kaufmann.

CIO (2015).GiyilebilirTeknolojiDünyayıDeğiştirecek, http://www.cio.com.tr, (02.01.2020).

Dinç, O. (2018). Mobil Uyumlu Web site ArayüzlerindeKullanılabilirlik, Işık Üniversitesi, SosyalBilimlerEnstitüsü, YüksekLisansTezi.

Dix, A., Finlay, J., Abowd, G. D., ve Beale, R. (2004).Human-Computer Interaction (3.Baskı). Essex, İngiltere: Pearson Education Limited.

Düz, N. (2001). KitapKapağındaGrafikTasarımÖgelerineveillkelerineKuramsalBirYaklaşım, YüksekLisansTezi, SüleymanDemirel Üniversitesi SosyalBilimlerEnstitüsü, Isparta.

Fonseca, R.S.V.S. (2011). Reading Pictograms and Signs- The Need for Visual Literacy, Master Thesis, UniversitetetiStavenger, Faculty of Arts and Education, Stavenger.

Gürses, E.A. (2006). Kütüphane Web SitelerindeKullanılabilirlikveKullanılabilirlikilkelerineDayalıTasarım, DoktoraTezi, Hacettepe Üniversitesi SosyalBilimlerEnstitüsü, Ankara.

İnançUyan, B. (2008).Internet PortallarınınGrafikTasarımAçısındanincelenmesi, Gazi Üniversitesi SanatveTasarımıDergisi, (2), $179-202$.

McDougall, S.J.P. and Reppa, I. (2008). Why do I like it? The relationships between icon characteristics, user performance and aesthetic appeal, Human Factors and Ergonomics Society 52nd Annual Meeting, New York

Mıhcı, C. (2014). ProgramlamaEğitimindeGörsel Blok Programlamave Mobil Uygulama Geliştirme AraçlarınınKarşılaştırılması, YüksekLisansTezi, Marmara Üniversitesi EğitimBilimleriEnstitüsü, İstanbul.

Namlı, Ç. (2010). Mobil Uygulama KullanılabilirliğininDeğerlendirilmesi, YüksekLisansTezi, İstanbul Teknik Üniversitesi Fen BilimleriEnstitüsü, İstanbul. 